\title{
The in vitro bioactivity of two novel hydrophilic, partially degradable bone cements
}

\author{
Luciano F. Boesel ${ }^{\text {a,b,*, }}$, Sandra C.P. Cachinho ${ }^{\text {c }}$, Maria H.V. Fernandes ${ }^{\text {c }}$, Rui L. Reis ${ }^{\text {a,b }}$ \\ a 3B's Research Group - Biomaterials, Biodegradables and Biomimetics, University of Minho, Campus of Gualtar, 4710-057 Braga, Portugal \\ ${ }^{\mathrm{b}}$ Department of Polymer Engineering, University of Minho, Campus of Azurém, 4800-058 Guimarães, Portugal \\ ${ }^{\mathrm{c}}$ Department of Ceramics and Glass Engineering, CICECO, University of Aveiro, 3810-193 Aveiro, Portugal
}

Received 13 April 2006; received in revised form 11 September 2006; accepted 25 September 2006

\begin{abstract}
Composite bone cements were prepared with bioactive glasses $\left(\mathrm{MgO}-\mathrm{SiO}_{2}-3 \mathrm{CaO} \cdot \mathrm{P}_{2} \mathrm{O}_{5}\right)$ of different reactivities. The matrix of these so-called hydrophilic, partially degradable and bioactive cements was composed of a starch/cellulose acetate blend and poly(2-hydroxyethyl methacrylate). The addition of $30 \mathrm{wt} . \%$ of glasses to this system made them bioactive in acellular medium: a dense apatite layer formed on the surface after 7 days of immersion in simulated body fluid. This was demonstrated both by microscopic and infrared spectroscopic techniques. The composition of the glass and, consequently, its structure was found to have important effects on the rate of the apatite formation. The combination of reactivity obtained by one formulation with the hydrophilic and degradable character of these cements makes them a very promising alternative to conventional acrylic bone cements, by allowing a better stabilization of the implant and a stronger adhesion to the bone.
\end{abstract}

(C) 2006 Acta Materialia Inc. Published by Elsevier Ltd. All rights reserved.

Keywords: Acellular bioactivity; Bioactive glasses; Acrylic cements; Degradable polymer; Hydrophilic

\section{Introduction}

The main cause of failure of cemented arthroplasties is the aseptic loosening of the prosthesis, which usually occurs at the cement-bone interface (considered to be the weakest link in the implant system [1]) and requires a second surgery for replacement of the whole system. A variety of causes have been proposed for this problem [2-4]: thermal necrosis of bone due to the high exothermic temperature of cement polymerization, chemical necrosis of bone due to the release of unreacted methylmethacrylate (MMA), shrinkage during polymerization, weakness of the cement (and the interfaces) when compared with the

\footnotetext{
${ }^{*}$ Corresponding author. Address: Department of Polymer Engineering, University of Minho, Campus of Azurém, 4800-058 Guimarães, Portugal. Tel.: +351 253510395 .

E-mail address: lfboesel@dep.uminho.pt (L.F. Boesel).
}

prosthesis, and the bone and stress shielding of the bone due to improper transfer of load. The determining factor, however, is the lack of strong interaction between the cement and the bone, since the only source of adhesive strength is the interdigitation of the cement with the bone, without any apparent chemical lock [5].

Increasing the interfacial strength between bone and cement is essential to achieving good performance of the prosthesis. The most studied method to obtain such improvement is by incorporating bioactive fillers in bone cements, creating a surface-bioactive material, i.e. a material that is able to establish a direct bond to bone [6]. Although bone particles $[7,8]$ and growth hormones $[9,10]$ have been used for this, bioactive glasses [11] or glassceramics $[12,13]$ and hydroxylapatite (HA) $[14-16]$ are the most promising and studied fillers. Besides imparting bioactive character to the cements, these fillers additionally improved compressive, tensile and flexural properties. 
However, two main problems exist with these formulations [6,17]: (i) in some cases, the amount of filler that can be included without deleterious effects on the mechanical or handling properties is so small that the increase in bioactivity is not likely to be very large; (ii) the glass or ceramic fillers tend to make poly(methylmethacrylate) (PMMA), an already brittle material, even more brittle. One way to take advantage of the bioactive potential and mechanical reinforcement of such fillers is by changing the matrix formulation, creating a cement with higher ductility and lower modulus. Such cement allows greater axial movement of the stem relative to the bone, increasing proximal load transfer, and acts as a load spreader, resulting in a more even load transmission between prosthesis and bone [6]. As brittleness is not a major concern, high amounts of filler can be added, improving mechanical properties and imparting a strong bioactive behavior to the cement.

Hydrophilic, degradable and bioactive cements (HDBCs) were developed with this aim in mind $[2,18]$. They contain an hydrogel-forming monomer (2-hydroxyethyl methacrylate, HEMA) in the liquid component of the typical bone cement formulation, partially substituted for MMA in order to adjust the mechanical and the swelling properties of the system. Therefore, the key characteristics of hydrophobic, acrylic cements, such as fast polymerization rate, injectability and high mechanical properties are maintained; and the advantages of hydrogels - good compatibility with body fluids and tissues, improved release behavior of drugs, easier surface reactivity [19], etc. - are added. After swelling, the ductility and energy to fracture are greatly improved, reaching a maximum 7 days after immersion [20]. These hydrophilic bone cements also incorporate a starch-based blend that can degrade in the body and has already been studied for a range of biomedical applications such as scaffolds for tissue engineering [21,22], systems for drugdelivery $[23,24]$, hydrogels $[25,23]$, and bone replacement and regeneration applications [26,27]. These cements could be made bioactive by the addition of bioactive fillers such as HA, as has been previously shown [28]. The bioactive filler additionally increases the mechanical properties of the dry formulations [11]. However, in previous experiments we used a combination of low-reactivity glass with a monomer (acrylic acid, AA) that had an inhibitory effect on the apatite growth. Due to this fact, AA was later replaced by HEMA [29], which lead to an increase on the surface reactivity, for the same kind of glass.

The aim of the present work was to study the in vitro bioactive behavior of HDBCs containing HEMA. The fillers were, as previously stated, surface-reactive glasses of the $3 \mathrm{CaO} \cdot \mathrm{P}_{2} \mathrm{O}_{5}-\mathrm{SiO}_{2}-\mathrm{MgO}$ system. However, this time two glasses of higher reactivity were chosen [30], in order to minimize the problems found in the previous formulations. The formulations were immersed in simulated body fluid $(\mathrm{SBF})$ and their surface was extensively characterized with spectroscopic and microscopic techniques.

\section{Materials and methods}

Specimens were prepared by adding the solid component to the liquid component. The solid was constituted by a commercial corn starch/cellulose acetate 50/50 wt.\% blend (SCA, Novamont, Italy) and one of two bioactive glasses (Mg31 and Mg36). The glasses were produced by the authors and their preparation is described in Ref. [30]. Their composition, particle sizes and surface area are shown in Table 1. These glasses have been selected in a compositional series, studied in a previous work [30], where the $\mathrm{SiO}_{2} / \mathrm{MgO}$ ratio is kept constant and correponds to the higher $\mathrm{MgO}$ contents tested in that work. Particle size was determined by laser scattering analysis using a Coulter LS100 particle size analyser; the values reported correspond to the mean values of particle size. The specific surface area was measured in a Micrometrics-Gemini 2370 V5, by nitrogen adsorption using the Brunauer, Emmett and Teller (BET) isotherm. The polymer particles were smaller than $125 \mu \mathrm{m}$, determined by sieving the powder and collecting the fraction smaller than this size. The liquid was constituted by 2-hydroxyethyl methacrylate (HEMA, Fluka, Germany), which was used as received. Benzoyl peroxide powder (BPO, Merck, Germany) was used as the polymerization initiator at a molar concentration of 0.01 with respect to the monomer amount. Dimethyl-p-toluidine (DMT, Aldrich, Germany) was used as the activator of the initiator, at a molar concentration of 0.67 with respect to the BPO amount. The solid/liquid ratio employed was $65 / 35$ (by mass) and the concentration of the glass was fixed at $32.5 \mathrm{wt} . \%$ of the total mass (i.e. $50 \mathrm{wt} \%$ of the solid component). The two formulations were named as $\mathrm{BC} 31$ and $\mathrm{BC} 36$, according to the glass used.

The preparation of specimens for subsequent tests was carried out following the traditional method. The activator DMT was dissolved in the liquid phase. The initiator of free radical polymerization reaction was added to the solid phase. Both phases were mixed and stirred by hand until the mixture became paste-like with a high viscosity; the mass was then placed into a poly(tetrafluoroethylene) (PTFE) mold to allow it to cure.

The in vitro bioactive behavior of the prepared bone cement formulations was studied over a period of 30 days in acellular medium. Prismatic specimens $(20 \mathrm{~mm} \times$ $4 \mathrm{~mm} \times 1.5 \mathrm{~mm}$ ) were immersed immediately after preparation in $13 \mathrm{ml}$ of a SBF $\left(142.0 \mathrm{mM} \mathrm{Na}^{+}, 5.0 \mathrm{mM} \mathrm{K}^{+}\right.$, $2.5 \mathrm{mM} \mathrm{Ca}^{2+}, 1.5 \mathrm{mM} \mathrm{Mg}^{2+}, 147.8 \mathrm{mM} \mathrm{Cl}^{-}, 4.2 \mathrm{mM}$ $\mathrm{HCO}_{3}^{-}, 1.0 \mathrm{mM} \mathrm{HPO}_{4}^{2+}, 0.5 \mathrm{mM} \mathrm{SO} \mathrm{SO}_{4}^{2-}$ ). The specimens were removed at intervals of $1,3,4,7,9,14$ and 30 days; they were taken out of the solution, rinsed with distilled water and dried at room temperature. After drying, the specimens were stored at $23{ }^{\circ} \mathrm{C}$ and $55 \%$ humidity. Aliquots of solution $(2 \mathrm{ml})$ were taken at the same test times from the containers to measure the concentration of the elements $\mathrm{Ca}, \mathrm{P}, \mathrm{Si}$ and $\mathrm{Mg}$ by inductively coupled plasma (ICP) emission spectroscopy using a Jobin-Yvon JY70 Plus spectrometer. 
Table 1

Molar composition and properties of the used glasses

\begin{tabular}{lllllll}
\hline Glass & $\mathrm{SiO}_{2}(\%)$ & $\mathrm{CaO}(\%)$ & $\mathrm{P}_{2} \mathrm{O}_{5}(\%)$ & $\mathrm{MgO}(\%)$ & Particle size $(\mu \mathrm{m})$ & Specific surface $\operatorname{area}\left(\mathrm{m}^{2} / \mathrm{g}\right)$ \\
\hline $\mathrm{Mg} 31$ & 25.37 & 32.62 & 10.87 & 31.14 & 11.3 & 0.284 \\
$\mathrm{Mg} 36$ & 29.37 & 25.96 & 8.65 & 36.02 & 10.2 & 0.233 \\
\hline
\end{tabular}

Surface modifications of the materials were studied by scanning electron microscopy (SEM) on a Leica Cambridge S360 microscope. When high magnifications were used, a Hitachi S-4100 microscope was employed. This microscope had an associated energy dispersive spectroscopy (EDS) equipment with semi-quantitative calibration; this allowed the calculation of the relative amounts of specific elements on the layer. All specimens were carbon covered before SEM/EDS analysis.

The specimen's surface was also analyzed with a Fourier-transformed infrared (FTIR) spectrophotometer with an attenuated total reflectance (ATR) module. The equipment employed was a Perkin-Elmer 1600 series, with a spectral resolution of $4 \mathrm{~cm}^{-1}$. Non-sintered hydroxyapatite (HA), with a particle size in the range $4.1-9.0 \mu \mathrm{m}$, was obtained from Plasma Biotal, UK, and used only for comparative purpose in infrared spectroscopy.

\section{Results}

SEM micrographs (Fig. 1(a-d)) showed that precipitates were present on the surface of $\mathrm{BC} 31$ after 4 days of immersion in SBF. After 1 day, the surface changed considerably (as compared to the non-immersed specimens), but no deposits were visible even at highmagnifications. A dense and thick layer was present after 9 days of immersion. Fig. 1(e) shows a high-magnification micrograph of a specimen after 4 days of immersion; the starter agglomerates, prior to layer formation, can be clearly seen in greater detail (white arrow). Fig. 1(f) and $1(\mathrm{~g})$ shows high-magnification micrographs of specimens immersed for 7 days in the SBF. A needle-like "cauliflower" morphology is clearly visible. As discussed later, this morphology is typical of apatite formation.

A comparison between both samples is showed in Fig. 2. The surface of BC36 (Fig. 2(a)) was covered by sparse precipitates and a few small agglomerates. The surface of BC31 (Fig. 2(b)), on the other hand, was covered by a dense layer.

Fig. 3 shows a comparison of the EDS spectra of formulation BC31 before and after immersion in SBF. Fig. 3(a) shows the presence of all elements that constitute the glass $(\mathrm{Mg}, \mathrm{Si}, \mathrm{P}$ and $\mathrm{Ca})$. After 7 days of immersion, only $\mathrm{Ca}$ and $\mathrm{P}$ are detected; the other elements (plus $\mathrm{Cl}$ from the solution) are present in residual amounts on the surface. Fig. 3(c) shows a spectra of one of the precipitates displayed in Fig. 1(e), proving that these deposits are formed from $\mathrm{Ca}$ and $\mathrm{P}$ and are, therefore, the initiators of the apatite formation. Based on these spectra, the atomic ratios of $\mathrm{Ca} / \mathrm{P}$ were calculated for each immersion period and are displayed in
Table 2; the ratio initially decreased, but started to increase after the build-up of the first precipitates.

Fig. 4 shows the ICP curves for both formulations. The profiles are similar: the concentration of $\mathrm{Ca}$ and $\mathrm{P}$ initially increased, then started to decrease after 3 days of immersion; on the other hand, $\mathrm{Mg}$ and $\mathrm{Si}$ concentrations increased continuously. For all elements shown there (except for $\mathrm{Si}$ ), the concentration in solution was higher for the formulation containing Mg31 than for the one containing $\mathrm{Mg} 36$.

FTIR was also used to characterize the surface of the specimens. Fig. 5(a) presents the spectra of BC31 and its three main constituents. The influence of each substance/ material is visible in the spectrum of the bone cement: a large and intense band centered at $1050 \mathrm{~cm}^{-1}$, due to the stretching of $\mathrm{Si}-\mathrm{O}$ bonds of the glass; an intense band centered at $1750 \mathrm{~cm}^{-1}$, due to the stretching vibrations of ester $(\mathrm{C}=\mathrm{O})$ linkages present in both HEMA and SCA; a weak band at $\sim 2950 \mathrm{~cm}^{-1}$ due to the stretching of alkyd bonds; and a large and a weak band centered at $3400 \mathrm{~cm}^{-1}$ due to the stretching vibrations of $\mathrm{OH}$ groups present in HEMA, SCA and the water molecules incorporated in them. Fig. 5(b) shows the spectra of BC31 after 1 and 14 days of immersion, as well as a spectrum of non-sintered HA for comparison.

\section{Discussion}

The first step in the evaluation of the bioactivity of any biomaterial is the study of its in vitro reactivity and ability to form a calcium phosphate layer when immersed in SBF. Materials that are successful in this preliminary in vitro test, i.e. which develop the layer, are considered to bond directly with bone [31]. Typically, polymers (such as bone cements) do not possess this property, and need to be loaded with bioactive fillers in order to do so. However, as we have previously shown, this condition is necessary, but not sufficient [11]: depending on the monomer used in the bone cement formulation, even high-reactivity glasses can only nucleate small $\mathrm{Ca}-\mathrm{P}$ agglomerates, without forming a layer. Therefore, a different monomer (HEMA) was later employed, and the calcium phosphate layer was, in this case, formed.

In this work, we employed an HEMA cement compounded with two bioactive glasses, more reactive than the one previously used [11]. Both glasses imparted acellular bioactivity to the formulations, although $\mathrm{Mg} 31$ was more reactive than $\mathrm{Mg} 36$, as shown in Fig. 2: even after 14 days in SBF, BC36 presented only small agglomerates of $\mathrm{Ca}-\mathrm{P}$ on its surface, while a dense layer had formed 

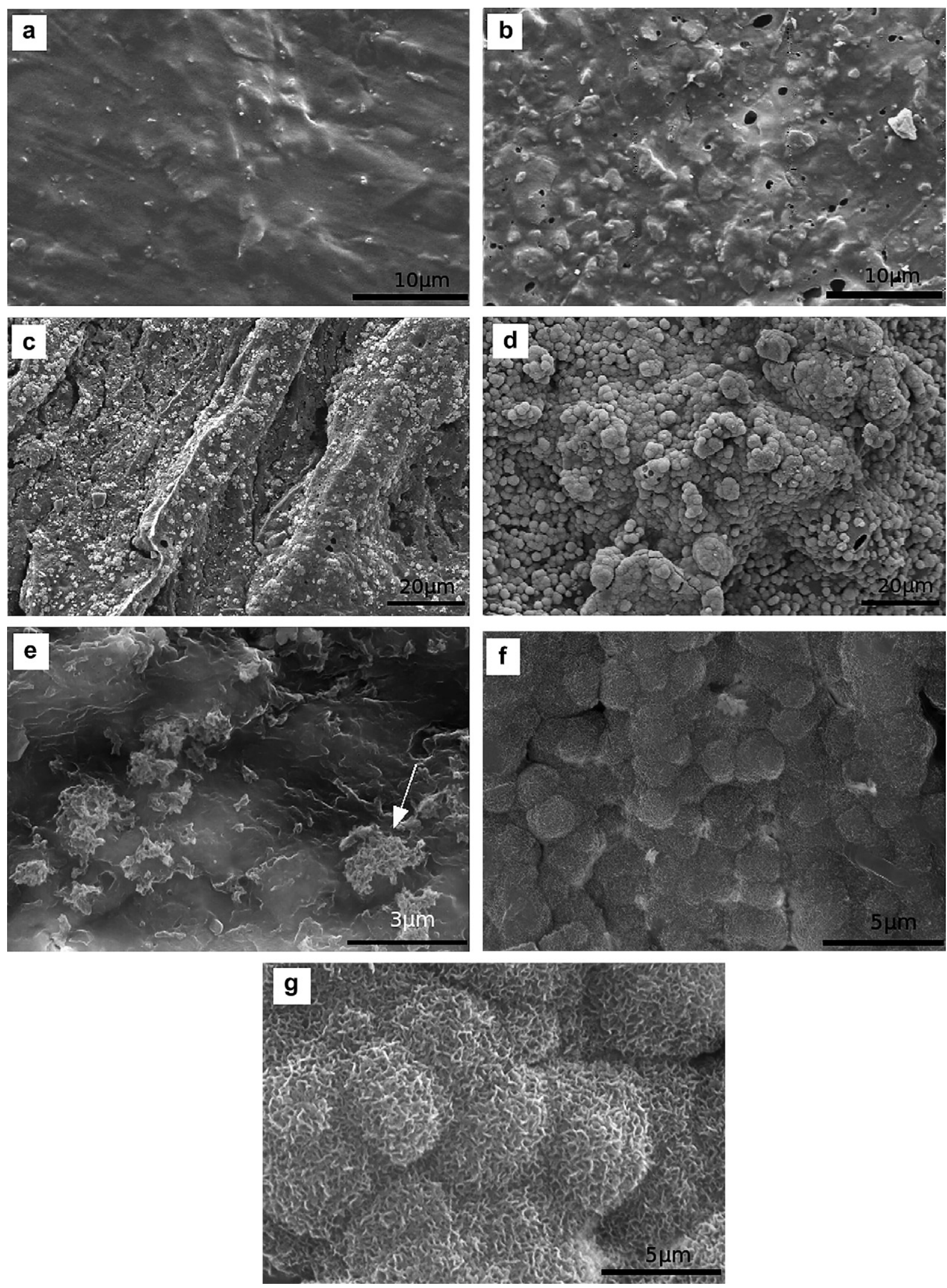

Fig. 1. SEM micrographs of the surface of specimens of BC31 immersed in SBF for 0 (a), 1 (b), 4 (c) and 9 (d) days. High-magnification SEM micrographs of the surface of specimens of BC31 immersed in SBF for 4 (e) and 7 (f, g) days. 

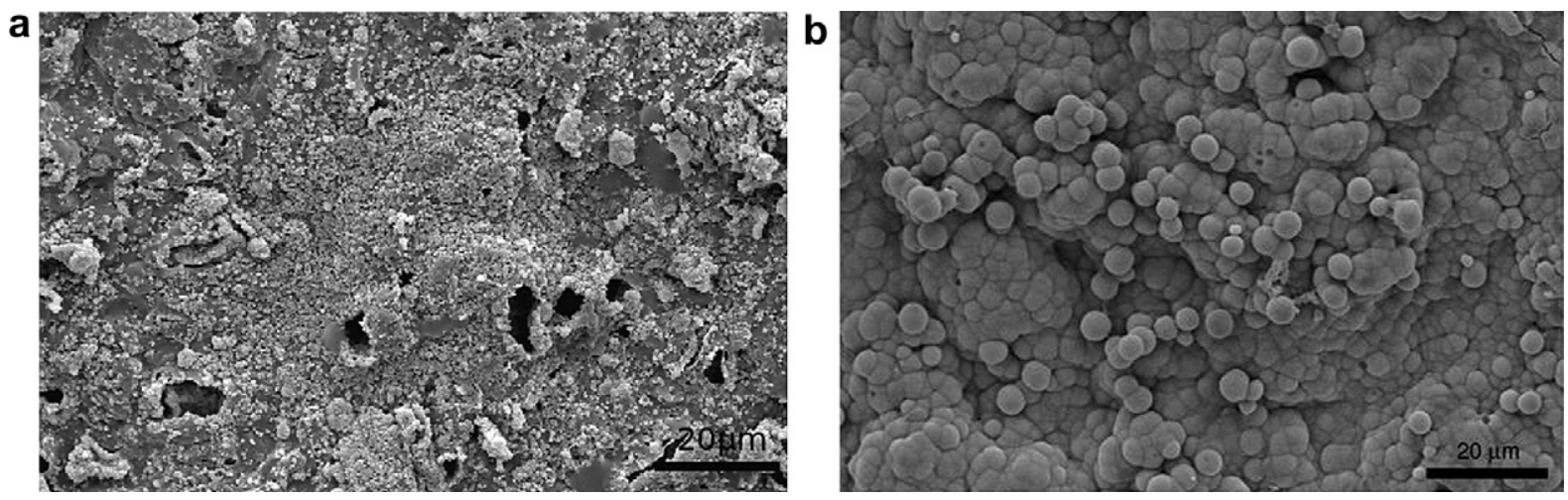

Fig. 2. SEM micrographs of the surface of specimen of BC36 (a) and BC31 (b) after 14 days of immersion in SBF.

on the surface of $\mathrm{BC} 31$. This observation correlated with the ICP curves shown in Fig. 4: after the initial period of increase in the concentration of $\mathrm{Ca}^{2+}$ and $\mathrm{PO}_{4}^{3-}$ in $\mathrm{SBF}$ (corresponding to the elements $\mathrm{Ca}$ and $\mathrm{P}$ in the figure), the decrease in the concentration was more intense for the solution corresponding to $\mathrm{BC} 31$ (for both elements), meaning that a greater amount of calcium and phosphorous was being consumed from the solution due to their precipitation as a layer. In the first day after immersion, higher amounts of both $\mathrm{Ca}^{2+}$ and $\mathrm{PO}_{4}^{3-}$ were released from $\mathrm{BC} 31$ to the solution, which might be expected due to the higher amounts of these elements in the composition of $\mathrm{BC} 31$ as compared to $\mathrm{BC} 36$. These results are in agreement with those obtained with the same glasses in bulk form [30]: in that study, the layer formed on the surface of a bulk specimen of $\mathrm{Mg} 31$ was thicker than that formed on the surface of $\mathrm{Mg} 36$; moreover, the concentration of $\mathrm{Ca}^{2+}$ and $\mathrm{PO}_{4}^{3-}$ started to decrease on the first day for $\mathrm{Mg} 31$ but only on the second day for Mg36. Similarly, in the case of our cements, the concentration of $\mathrm{Ca}^{2+}$ started to decrease on the first day for $\mathrm{BC} 31$, but only after the third day for $\mathrm{BC} 36$. This fact may be related to the composition of the two glasses. Mg31 contains less silica than Mg36 and a higher amount of network modifiers. Continuous leaching of calcium and magnesium to the solution may be responsible for the disruption of the main silica network, thus promoting a faster and more extensive dissolution of silica. Additionally, this glass $(\mathrm{Mg} 31)$ contains more $\mathrm{CaO}$ and $\mathrm{P}_{2} \mathrm{O}_{5}$, which, when dissolved, contribute for saturating the solution and expediting the apatite formation.

The ICP results indicate that precipitation of $\mathrm{Ca}-\mathrm{P}$ should start on the first day (for BC31), which was not observed microscopically (Fig. 1(b)). As outlined previously, this was probably due to the magnifications that could be attained with both microscopes. Only at 4 days were the precipitates large enough to be observed. These aggregates, as shown in the spectra of Fig. 3(c), were formed mainly of $\mathrm{Ca}$ and $\mathrm{P}$, consumed from the solution. For all immersion times in SBF the ionic concentration of $\mathrm{Ca}^{2+}$ is always higher than the initial one, for zero time, and the ionic concentration of $\mathrm{PO}_{4}^{3-}$ slightly decreases. Since SEM micrographs and EDS analysis clearly showed the presence of a $\mathrm{Ca}-\mathrm{P}$ layer, it becomes obvious that $\mathrm{Ca}^{2+}$ and $\mathrm{PO}_{4}^{3-}$ from the solution have been previously provided by the glass itself, which is highly soluble in the plasmatic solution. The observed apatite layer is thus the result of a complex reprecipitation process. After 4 days, $\mathrm{Si}$ and $\mathrm{Mg}$ are still present in relevant amounts. As the time of immersion increases, the precipitates originate a dense layer of $\mathrm{Ca}-\mathrm{P}$, and the amounts of other elements become residual. After long immersion times, it seems that some $\mathrm{Cl}$ from the SBF is incorporated in the layer. For similar time periods, the EDS spectrum of BC36 (data not shown) shows much more intense peaks for $\mathrm{Si}$ and $\mathrm{Mg}$, proving that the layer was thinner and not totally covering the surface, allowing the appearance of the peaks coming from the glass.

Due to this difference between the reactivity of the two glasses, only BC31 was chosen for further characterization. This included FTIR spectroscopy and semi-quantitative EDS analysis. The evolution of the spectra with immersion time confirms the previous discussion: at 1 day, no difference could be seen in the curves and the spectrum remained identical to that of the original sample; however, after 14 days the bands disappeared and only a strong and large band at $1000 \mathrm{~cm}^{-1}$ is seen. The comparison with a spectrum of non-sintered HA shows the similarity between both spectra, and makes it possible to assign the observed band to the phosphate groups present in HA or other calcium phosphate minerals.

The evolution of the $\mathrm{Ca} / \mathrm{P}$ ratio shown in Table 2 indicates that, initially, a different calcium phosphate phase is formed, which is either amorphous or crystalline. As the precipitates grew to form a layer, the ratio also grew, approaching that of HA. After 1 week, the value stabilized at $\mathrm{Ca} / \mathrm{P}=1.59$. The atomic $\mathrm{Ca} / \mathrm{P}$ ratio is 1.67 in stoichiometric HA; however in bone, as well as in layers precipitated on bioactive materials, this value is usually lower due to the presence of carbonates, forming hydroxycarbonate apatite (HCA) [32].

These results, together, demonstrated that the developed composites induce the nucleation and growth of an apatite layer when immersed in SBF. This is a strong indication that these materials should exhibit high bone-bonding 


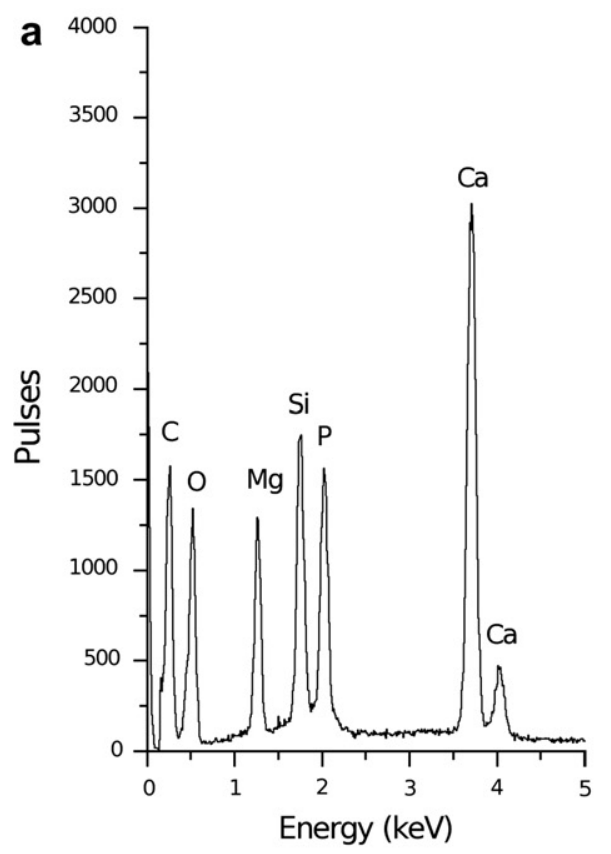

b

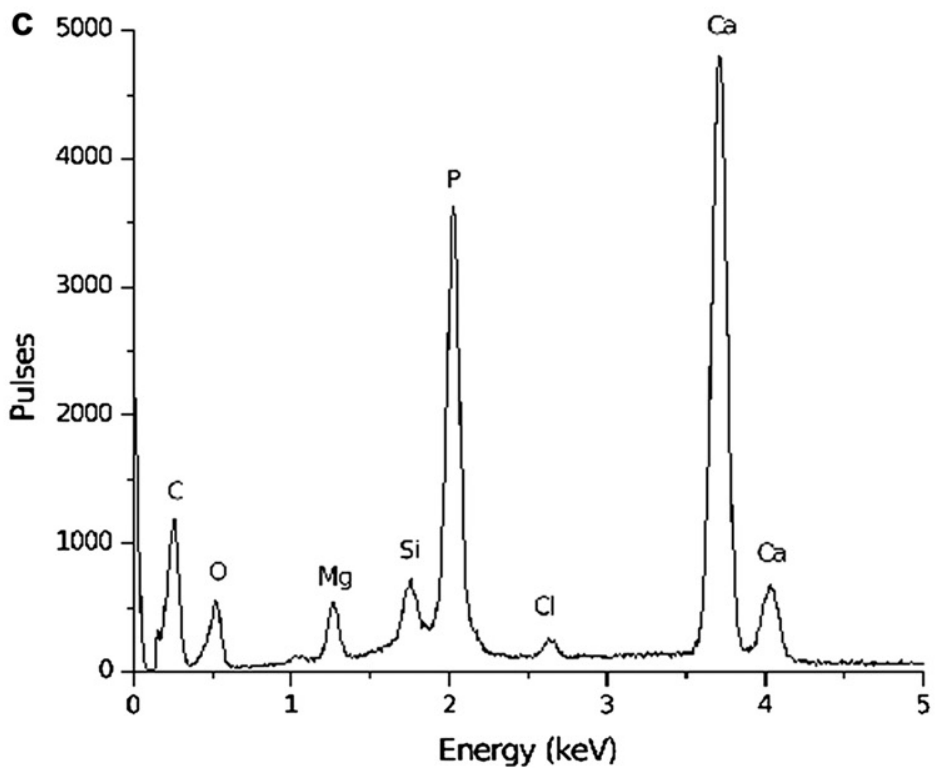

Fig. 3. EDS spectra of the surface layer of BC31 before (a) and after (b) 7 days of immersion in SBF. (c) EDS spectrum of the precipitate indicated in Fig. 1(e).

Table 2

Evolution of $\mathrm{Ca} / \mathrm{P}$ atomic ratio as function of immersion time of formulation $\mathrm{BC} 31$ in SBF, as determined by EDS analysis

\begin{tabular}{ll}
\hline Time of immersion (days) & $\mathrm{Ca} / \mathrm{P}$ (atomic ratio) \\
\hline 0 & 1.82 \\
4 & 1.38 \\
7 & 1.59 \\
14 & 1.59 \\
\hline
\end{tabular}

potential in vivo. But, due to the other characteristics of these HDBCs, this property will be potentiated. In other papers, we have shown that the hydrophilicity of these materials allows them to exert compressive forces on the

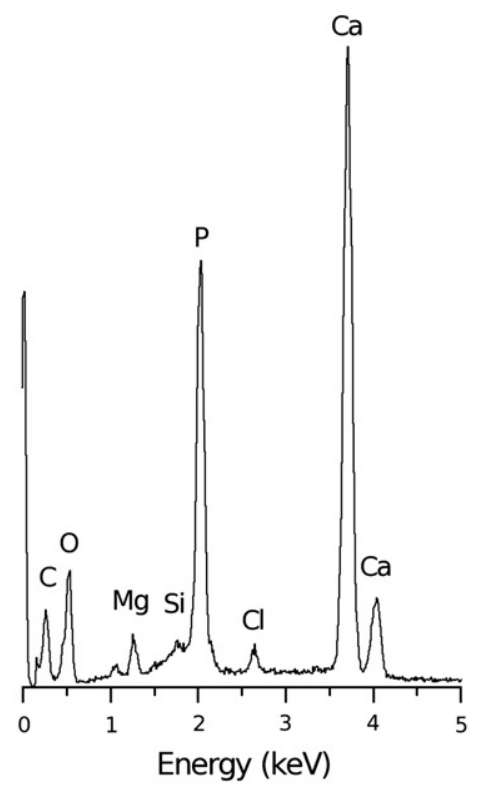




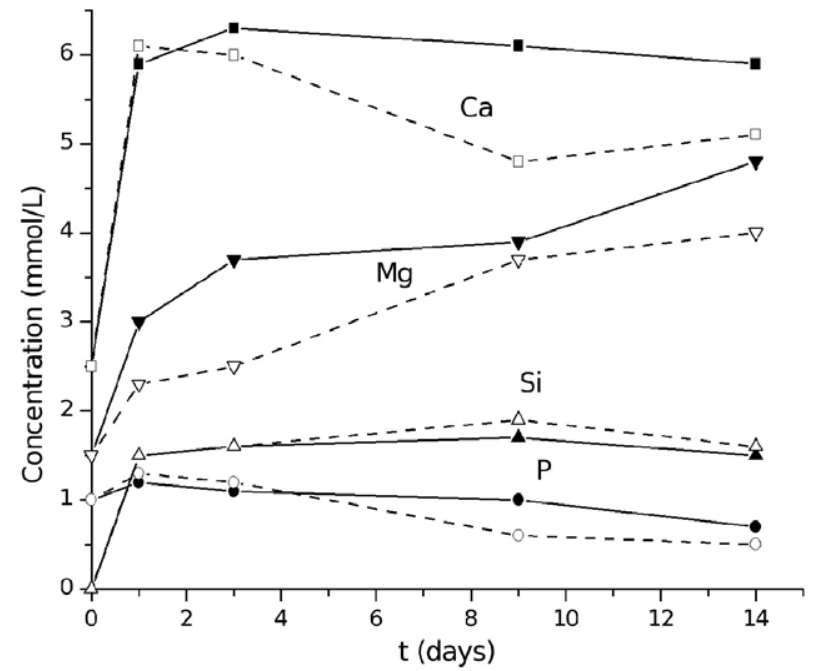

Fig. 4. Elemental concentration as a function of immersion time for $\mathrm{BC} 31$ $(--)$ and $\mathrm{BC} 36(-)$.
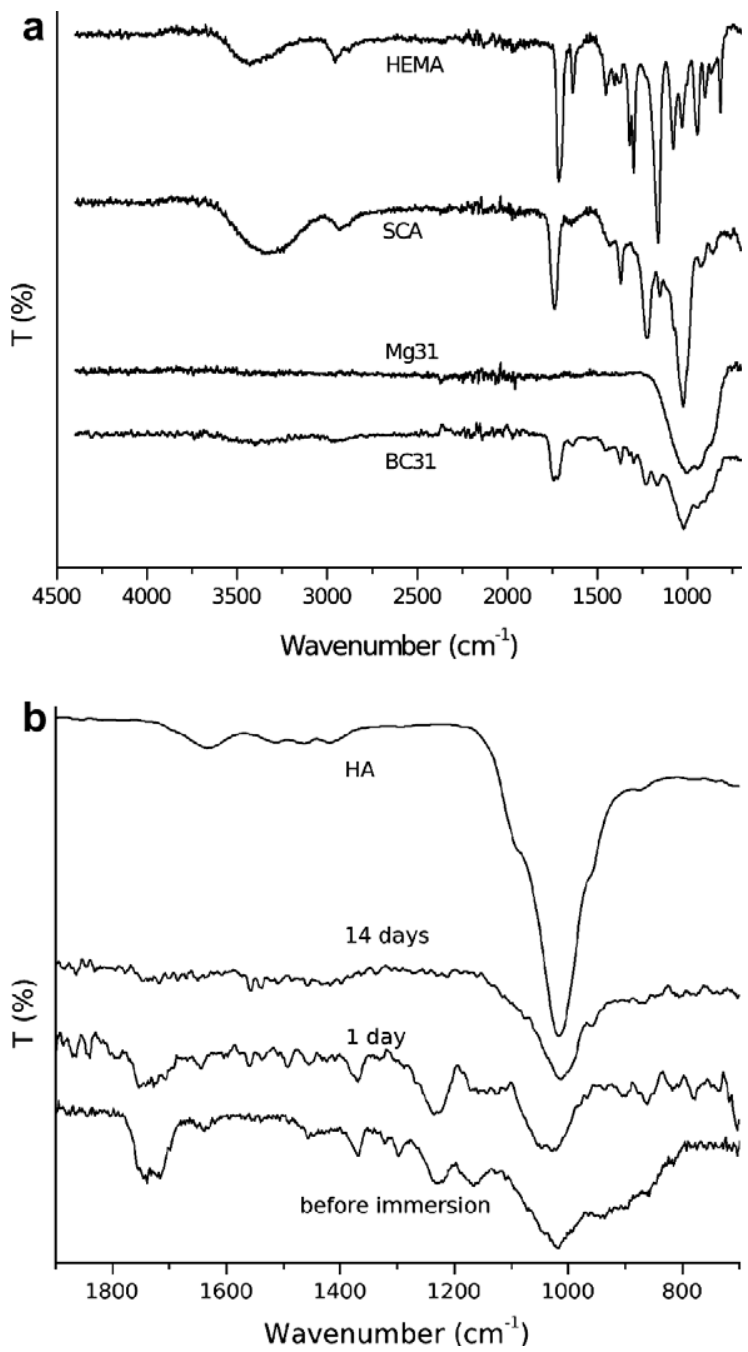

Fig. 5. (a) FTIR spectra of BC31 and its 3 main constituents (HEMA, SCA and Mg31). (b) FTIR spectra of BC31 before and after 1 and 14 days of immersion in SBF, and the spectrum of HA for comparison. inducing bioactivity, also helps to increase the mechanical properties of the cements and their doughing time [11]. The next steps in this research will be (i) to perform simultaneous tests of degradation and bioactivity, to confirm the hypothesis above, and, if this proves successful, (ii) also to perform in vivo tests to assess the compatibility of the cements with the surrounding tissues. Moreover, glass Mg36 will be heat treated to produce a glass-ceramic, which would improve mechanical properties and promote better adhesion of the layer to the cement's surface [35], although this might lead to a decrease in its bioactivity.

\section{Conclusion}

We have developed novel HDBCs that contain degradable starch-based blends and bioactive glasses. The composition of the glass was an important parameter controlling the kinetics of apatite growth on the surface of the cement, and formulations with high-reactivity could be obtained by using the proper glass. These cements are a promising alternative to conventional bone cements, due to the excellent combination of mechanical, curing, degradation and bioactive properties. The results of the in vitro tests reported herein allow one to predict a positive behavior in future in vivo studies. If the bioactivity is confirmed in animal and clinical tests, it should promote bone formation on the surface of the cement in contact with bone and, if coupled with an adequate degradation profile, would also allow bone ingrowth inside the pores of the partially degraded cement.

\section{Acknowledgements}

L.F. Boesel acknowledges Fundação Coordenação de Aperfeiçoamento de Pessoal do Ensino Superior (CAPES - Brasília, Brazil) for a PhD grant. This work was partially supported by FCT Foundation for Science and Technology, through funds from the POCTI and/or FEDER programmes.

\section{References}

[1] Keller JC, Marshall GW, Lautenschlager EP. Morphological identity of porosity in chemically activated acrylic cements. Scanning Electron Microscopy 1979;1:425-34.

[2] Boesel LF, Mano JF, Elvira C, San Román J, Reis RL. Hydrogels and hydrophilic partially degradable bone cements based on biodegradable blends incorporating starch. New York: Kluwer Academic/ Plenum Press; 2003, p. 243-260.

[3] Deb S. A review of improvements in acrylic bone cements. J Biomater Appl 1999;14:16-48.

[4] Lewis G. Properties of acrylic bone cements: state of the art review. J Biomed Mater Res: Appl Biomater 1997;38:155-82.

[5] Lautenschlager EP, Stupp SI, Keller JC. Structure and properties of acrylic bone cement, vol. 2. Boca Raton, FL: CRC; 1984, p. 87-119..

[6] Harper EJ. Bioactive bone cements. Proc Inst Mech Eng, Part H: J Eng Med 1998;212:113-20.

[7] Liu YK, Njus GO, Park JB, Stienstra D. Bone particle impreganted bone cement I. In Vitro Study. J Biomed Mater Res 1987;21: 247-261. 
[8] Henrich DE, Cram AE, Park JB, Lui YK, Reddi H. Inorganic bone and demineralized bone matrix impregnated bone cements: a preliminary in vivo study. J Biomed Mater Res 1993;27:277-80.

[9] Downes S, Wood DJ, Malcolm AJ, Ali SY. Growth hormone in polymethylmethacrylate cement. Clin Orthop Rel Res 1990;252: 294-8.

[10] Goodwin CJ, Braden M, Downes S, Marshall NJ. Investigation into the release of bioactive recombinant human growth hormone from normal and low-viscosity poly(methylmethacrylate) bone cements. J Biomed Mater Res 1997;34:47-55.

[11] Boesel LF, Fernandes MHV, Reis RL. The behaviour of novel hydrophilic composite bone cements in simulated body fluids. J Biomed Mater Res: Appl Biomater 2004;70B:368-77.

[12] Shinzato S, Kobayashi M, Mousa WF, Kamimura M, Neo M, Kitamura Y, Kokubo T, et al. Bioactive polymethyl methacrylatebased bone cement: comparison of glass beads, apatite- and wollastonite-containing glass-ceramics, and hydroxyapatite fillers on mechanical and biological properties. J Biomed Mater Res 2000;51:258-72.

[13] Mousa WF, Fujita H, Ido K, Neo M, Kobayashi M, Zeineldin IA, et al. Bone-bonding ability of bioactive bone cement under mechanical stress. J Biomed Mater Res: Appl Biomater 1999;48:726-33.

[14] Sogal A, Hulbert SF. Mechanical properties of a composite bone cement: Polymethylmethacrylate and hydroxyapatite, In: International symposium on ceramics in medicine, No. 5 in Proceedings, Kyoto, 1992, p. 213-224.

[15] Dalby MJ, di Silvio L, Harper EJ, Bonfield W. In vitro evaluation of a new polymethylmethacrylate cement reinforced with hydroxyapatite. J Mater Sci: Mater Med 1999;10:793-6.

[16] Harper EJ, Behiri JC, Bonfield W. Flexural and fatigue properties of a bone cement based upon polymethylmethacrylate and hydroxyapatite. J Mater Sci: Mater Med 1995;6:799-803.

[17] Mano JF, Sousa RA, Boesel LF, Neves N, Reis R. Bioinert, biodegradable and injectable polymeric matrix composites for hard tissue replacement: state of the art and recent developments. Compos Sci Technol 2004;64:789-817.

[18] Pereira CS, Cunha AM, Reis RL, Vázquez B, San Román J. New starch-based thermoplastic hydrogels for use as bone cements or drug-delivery carriers. J Mater Sci: Mater Med 1998;9(12):825-33.

[19] Taguchi T, Kishida A, Akashi M. Hydroxyapatite formation on/in poly(vinyl alcohol) hydrogel matrices using a novel alternate soaking process. Chem Lett 1998;8:711-2.

[20] Boesel LF, Reis RL. Novel partially degradable, hydrophylic bone cements incorporating starch: development and mechanical properties evolution, In: Annual Meeting of the Society for Biomaterials, No. 29 in Proceedings, Reno, 2003, p. 474.

[21] Gomes ME, Sikavitsas VI, Behravesh E, Reis RL, Mikos AG. Effect of flow perfusion on the osteogenic differentiation of bone marrow stromal cells cultured on starch-based three-dimensional scaffolds. J Biomed Mater Res 2003;67A:87-95.

[22] Pashkuleva I, Marques AP, Vaz F, Reis RL. Surface modification of starch based blends using potassium permanganate-nitric acid system and its effect on the adherence and proliferation of osteoblastic-like cells. J Mater Sci: Mater Med 2005;116:81-92.

[23] Baran ET, Mano JF, Reis RL. Starch-chitosan hydrogels prepared by reductive alkylation cross-linking. J Mater Sci: Mater Med 2004;15: 759-65.

[24] Silva GA, Costa FJ, Neves NM, Coutinho OP, Dias ACP, Reis RL. Entrapment ability and release profile of corticosteroids from starch-based microparticles. J Biomed Mater Res 2005;73A: $234-43$.

[25] Elvira C, Mano JF, San Román J, Reis RL. Starch-based biodegradable hydrogels with potential biomedical applications as drugdelivery systems. Biomaterials 2002;23(9):1955-66.

[26] Reis RL, Cunha AM, Allan PS, Bevis MJ. Structure development and control of injection-molded hydroxylapatite-reinforced starch/EVOH composites. Adv Polym Technol 1997;16(4):263-77.

[27] Sousa RA, Kalay G, Reis RL, Cunha AM, Bevis MJ. Injection molding of a starch/EVOH blend aimed as an alternative biomaterial for temporary applications. J Appl Polym Sci 2000;77:1303-15.

[28] Espígares I, Elvira C, Mano JF, Vázquez B, San Román J, Reis RL. New partially degradable and bioactive acrylic bone cements based on starch blends and ceramic fillers. Biomaterials 2003;23(8): 1883-95.

[29] Boesel LF, Reis RL. Hydrophilic matrices to be used as bioactive and degradable bone cements. J Mater Sci: Mater Med 2004;15:503-6.

[30] Pereira D, Cachinho S, Ferro MC, Fernandes MHV. Surface behaviour of high $\mathrm{MgO}$-containing glasses of the $\mathrm{Si}-\mathrm{Ca}-\mathrm{P}-\mathrm{Mg}$ system in a synthetic physiological fluid. J Eur Ceram Soc 2004;24(15-16):3693-701.

[31] Kokubo T, Kim HM, Kawashita M, Nakamura T. What kinds of materials exhibit bone-bonding? Toronto: Em2 Inc.; 2000, pp. 190194.

[32] Hench LL. Bioceramics: from concept to clinic. J Am Ceram Soc 1991;74(7):1487-510.

[33] Boesel LF, Reis RL. The effect of water uptake on the behaviour of hydrophilic cements in confined environments. Biomaterials 2006;27:5627-33.

[34] Boesel LF, Azevedo HS, Reis RL. Incorporation of $\alpha$-amylase enzyme and a bioactive filler into hydrophilic, partially degradable and bioactive cements (HDBCs) as a new approach to tailor their simultaneous degradation and bioactive behaviour. Biomacromolecules 2006;7:2600-9.

[35] Oliveira JM, Correia RN, Fernandes MH. Surface modifications of a glass and a glass-ceramic of the $\mathrm{MgO}-3 \mathrm{CaO} \cdot \mathrm{P}_{2} \mathrm{O}_{5}-\mathrm{SiO}_{2}$ system in a simulated body fluid. Biomaterials 1995;16(11):849-54. 